\title{
Xanthine Oxidase Activity in Patients with Sickle Cell Anaemia Presenting with Vaso-Occlusive Crises in University College Hospital, Ibadan
}

\author{
Odebiyi Hassan Abiola ${ }^{1, ~ *}$, Fasola Foluke Atinuke ${ }^{1,2}$ \\ ${ }^{1}$ Department of Haematology, University College Hospital, Ibadan, Nigeria \\ ${ }^{2}$ Department of Haematology, Faculty of Basic Medical Sciences, College of Medicine, University of Ibadan, University College Hospital, \\ Ibadan, Nigeria
}

\author{
Email address: \\ odebiyi_h@yahoo.com (O. Ha), folukefasola@yahoo.com (F. Fa) \\ ${ }^{*}$ Corresponding author
}

\section{To cite this article:}

Odebiyi Hassan Abiola, Fasola Foluke Atinuke. Xanthine Oxidase Activity in Patients with Sickle Cell Anaemia Presenting with VasoOcclusive Crises in University College Hospital, Ibadan. American Journal of Laboratory Medicine. Vol. 5, No. 2, 2020 , pp. 55-62. doi: 10.11648/j.ajlm.20200502.13

Received: June 2, 2020; Accepted: June 19, 2020; Published: July 4, 2020

\begin{abstract}
Recurrent bone pain or vaso-occlusive crisis (VOC) constitutes a major presentation in patients with sickle cell anaemia. This is partly attributable to vasospasm, oxidative stress and inflammation. Xanthine oxidase is released during VOC and it had been implicated in the pathogenesis of bone pain crisis in patients with sickle cell anaemia. This study was aimed at comparing the plasma levels of xanthine oxidase activity in adult patients with Sickle cell anaemia (SCA), during bone pain crisis (BPC) and steady state and correlating it with the severity of bone pain crisis. Thirty adult sickle cell anemia patients with BPC and 30 in steady state attending Haematology clinic at the University College Hospital, Ibadan, Nigeria and 30 normal haemoglobin A, age- and sex-matched controls were enrolled for this study. Severity of BPC was assessed with total summary pain score. Haematological parameters were determined by a 5-part autoanalyzer. Plasma xanthine oxidase activity was determined using enzyme linked immunosorbent assay (ELISA). Data obtained were analyzed using the Statistical Package for the Social Science (SPSS) version 20. Results were considered statistically significant if $\mathrm{p}<0.05$. Biochemical parameters were correlated with the severity of bone pain crisis. Plasma xanthine oxidase activity was significantly elevated in the BPC group than in the steady state group $(\mathrm{p}=0.000)$ and HbA group $(\mathrm{p}=0.000)$. There steady state group plasma xanthine oxidase activity was also significantly higher than that of HbA group (p-0.032). Similarly, the plasma Plasma xanthine oxidase activity was significantly higher in all BPC severity group than steady state group with associated significantly low positive correlation of xanthine oxidase activity and bone pain severity. This study established that plasma xanthine oxidase activity was higher in patients with SCA presenting in bone pain crisis than steady state and $\mathrm{HbA}$ individual with associated positive correlation between plasma xanthine oxidase activity and bone pain severity.
\end{abstract}

Keywords: Sickle Cell Anaemia, Plasma Xanthine Oxidase Activity, Bone Pain Crisis, Steady State, HbA

\section{Introduction}

Background of the study

Sickle cell anaemia (SCA) is a type of sickle cell disease (SCD) that is characterized by homozygous inheritance of $\mathrm{HbS}$. This is the most common and most severe form of sickle cell disorder [1]. Patients suffer acute episodic crises and chronic complications resulting in substantial morbidity and early death. The significant disease burden results in frequent hospitalizations, emergency department visits, loss of man - hour for patients and those who cares for them [2].

The most frequent morbidity in patient with SCA is episodic vaso-occlusive crises (VOC) which often present as bone pain crisis. The bone pain crisis severity is both objectively and subjectively measurable unlike VOC in 
other organs of the body. The bone pain may last few hours to 7 days, but some severe bone pain crisis may last for weeks [3]. This VOC is a consequence of obstruction of blood vessels by sickled red cells, resulting in ischaemia of affected tissues or organs supplied. A Vasoocclusive crisis is associated with intermittent cessation and restoration of blood flow (ischaemia-reperfusion (I/R)). This I/R cause production of Xanthine oxidase (XO) in the early phase of reperfusion. The production of $\mathrm{XO}$ during reperfusion is intricately linked with increase reactive oxygen species and tissue injury as well as impaired vascular relaxation.. XO is central to a series of oxidizing processes contributing to the pathogenetic process in sickle cell disease [4].

During the course of Ischaemia, energy in form of Adenosine triphosphate (ATP) is consumed leading to the dissipation of transmembrane ion gradients, this causes rise in the intracellular concentration of calcium, which leads to activation of protease that irreversibly converts Xanthine dehydrogenase $(\mathrm{XDH})$, predominant in vivo, to $\mathrm{XO}$. The trypsin inhibitor that inhibits the conversion of $\mathrm{XD}$ to $\mathrm{XO}$ during normal oxygenation is also suppressed.[5] At the same time, cellular ATP is catabolized to hypoxanthine, which accumulates in the endothelium [6].

During reperfusion, the blood supply is restored, $\mathrm{XO}$, using readmitted oxygen catalyzes the conversion of hypoxanthine to xanthine; during this process a molecule of superoxide is produced. The XO further catalyzes the conversion of xanthine to uric acid, during which another molecule of superoxide will also be produced. The two molecules of superoxide generated during these reactions can induce oxidative stress directly or indirectly (through its dismutation to hydrogen peroxide in the presence of superoxide dismutase) [6-8]. Xanthine Oxidase also generates reactive oxidants when it catalyzes reaction of nonhypoxanthine, non-xanthine compounds and substrates such as S-Nitrosothiols, peroxynitrite and acetaldehyde [9]. Other sources of oxidative stress in patients with sickle cell anaemia include: High cell-free haemoglobin [10] and elevated level of methaemoglobin derived from fast rate of auto-oxidation of $\mathrm{HbS}$ than $\mathrm{HbA}$ [11].

These reactive oxygen species cause endothelial injury which subsequently induce inflammatory reaction in the tissue [12]. The oxidative damage induces increase production of nicotinamide adenine dinucleotide phosphate (NADPH) oxidase (another ROS) released by polymorphonuclear cell and monocytes, which further causes a progressive tissue injury. In view of the aforementioned, XO accounts for the oxidative damage in the early phase of reperfusion while NADPH oxidase produced by polymorphonuclear leucocytes and monocytes act in later phase of reperfusion injury to cause progressive tissue damage [12]. The regional blood flow deprivation during sickle cell crises and the consequent oxygen radical-dependent tissue injury triggered by $\mathrm{XO}$ contribute significantly to painful episodes and vaso-occclusive crisis associated tissue damage.

Under normal circumstances, $\mathrm{H}_{2} \mathrm{O}_{2}$ derived from superoxide dismutation during VOC is removed by two enzymes: glutathione peroxidase (GPX) or catalase. There is reduction in the levels of GPX enzymes and glutathione in patients with SCD $[13,14]$, this makes it difficult for the clearance of the endogenously produced $\mathrm{H}_{2} \mathrm{O}_{2}$ [15]. Also, there is no consistency in the report on levels of catalase in SCD. A study showed reduced level of catalase, whereas another study observed increased levels in patients (which could be a protective effect to scavenge $\mathrm{H}_{2} \mathrm{O}_{2}$ ) [16]. These reductions in glutathione with its co-factor and catalase suggest that there is abundance of oxidative stress which leads to further consumption or inactivation of the few available protective elements in patients with sickle cell disease [17].

Animal studies demonstrated increased rates of xanthine oxidase (XO)-dependent vessel wall production of nitric oxide inactivating oxygen radicals in SCD [18]. Osarogiagbon et al. study also showed increased conversion of XD to XO and significant increase in the mean plasma XO in the sickle mice when exposed to 2hours of hypoxia as compared to sickle mice exposed to ambient air [18].

Researchers and several clinical trials have generated antisickling drugs such as hydroxyurea to reduce the incidence of painful crisis [19]. Recent studies have focused on the development of therapies that target specific pathophysiological mechanisms of the disease, as either preventative or abortive approaches to VOC [20]. A study observed that heparin-induced dissociation of $\mathrm{XO}$ from vessel wall binding sites and allopurinol-mediated XO inhibition decrease vessel reactive oxygen production [21]. These are evidences supporting significant increase in the plasma XO activity and its role in pathophysiology of VOC in SCD patients, however, these have mainly been in animal studies A gap exist in these studies in SCD patients as they could not link XO with disease burden, patients outcome and disease process. In view of the paucity of these informations, xanthine oxidase activity was studied in patients with sickle cell disease in steady state, vaso-occlusive crisis in form of bone pain crises and $\mathrm{HbA}$ individuals.

\section{Materials and Methods}

The research was carried out in University College Hospital (UCH), Ibadan Nigeria from January 2018 to November 2018. Ethical approval was obtained from the University of Ibadan / University College Hospital Ethics Committee. Informed consent was obtained from each eligible participant before administering the questionnaire and blood sample collection.

\subsection{Inclusion and Exclusion Criteria}

The study population were (1) Patients with SCA in bone pain crisis: These were the patients whose $\mathrm{Hb}$ electrophoresis at alkaline $\mathrm{pH}$ result showed $\mathrm{HbS}$ and presented with sudden onset of bone or joint pain attributable to sickle cell anaemia. The bone or joint pain in the patient required clinic visit and analgesic administration [22]. (2) Patients with sickle cell 
anemia in steady-state: These were patients whose haemoglobin electrophoresis at alkaline $\mathrm{pH}$ was confirmed to be $\mathrm{HbS}$ who were well and without any symptoms or signs of overt infection, pain, or any other acute episode suggestive of crisis in the last 3 months [22]. (3) The controls were apparently healthy $\mathrm{HbA}$ individuals (adult students and hospital workers whose haemoglobin electrophoresis at alkaline $\mathrm{pH}$ were confirmed as $\mathrm{HbA}$ ).

The participants were excluded if: they [1] refuse to give consent, (2) smoke cigarette (3) take alcohol, (4) had coexisting sickle cell nephropathy, (5) had co-existing liver disease, (6) have co-existing malignancy, (7) are Obese (body mass index >30) (8) are on any medication such as ethambutol, pyrazinamide, cyclosporine, diuretics or allopurinol and (9) Sickle cell anaemic patients in bone pain crisis with clinical features of hyperhemolytic crisis such as passage of dark coloured urine, increasing yellowness of the eye.

\subsection{Study Design}

This is a comparative cross-sectional study in which the plasma xanthine oxidase activity (XO) of 30 age- and sexmatched adult patients each with sickle cell anaemia in bone pain crises (BPC), in steady state (SS) and normal $\mathrm{HbA}$ control were assessed.

The study participants filled questionnaires which contained sections on bio-data, past and present medical history and clinical assessment for the management of the bone pain crisis. Clinical severity of bone pains was assessed using a Total Summary Pain Score ((TSPS) which utilizes numerical rating scale, pain duration, patient's behavior and analgesics used [24]. It is simple and easy to use; it also takes into consideration patient's and doctor's perception of pain as summarized below:

Table 1. Total Summary Pain Score (TSPS).

\begin{tabular}{|c|c|c|c|c|}
\hline $\begin{array}{ll}\text { Characteristics } & \text { Score } \\
\end{array}$ & 1 & 2 & 3 & 4 \\
\hline Verbal pain score & $1-4$ & $5-6$ & $7-10$ & \\
\hline Duration of pain & Less than 3 days & 4-7 days & More than 7 days & \\
\hline Patient's behavior & Normal & Agitated & Very disturbed & Too quiet \\
\hline Intervention/analgesia & PCM/NSAIDs & Opioids & $\mathrm{PCA} / \mathrm{ICU}$ & \\
\hline
\end{tabular}

TSPS were calculated as follows:

TSPS $=$ [patient's pain score $\mathrm{X}$ duration of pain] + [patients behavior] + [analgesia used]

Interpretation:

Mild total summary pain score $=3-7$,

Moderate total summary pain score $=8-11$

Severe total summary pain score $=12-16$

Adult homozygous $\mathrm{HbS}$ patients (SCA) who fulfilled the criteria for the study and gave informed consent were consecutively enrolled as they presented at the Haematology Day Care Unit (HDCU) in bone pain crisis (BPC). They were categoried as BPC group. The patients in the steady state group were recruited from the weekly routine follow up clinic visit consecutively following informed consent. The control subjects were apparently healthy $(\mathrm{HbA})$ age- and sexmatched individuals with haemoglobin electrophoresis result of $\mathrm{HbA}$ done in University College Hospital Ibadan and without clinical evidence of SCD.

Questionnaires were administered to all participants by the researcher / attending Physician. Clinical severity of bone pain crisis in the BPC group was assessed using Total Summary Pain Score. The weight and height of the participants were measured with a weighing scale and physician mechanical beam scale with height rod. These indices were used to calculate the body mass index.

Eight milliliters of blood was collected with a sterile needle from all participants. Five milliliters of blood withdrawn was shared equally between two EDTA sample bottles. The sample in first EDTA sample bottle was used for analysis of full blood count, reticulocyte count and peripheral blood film review. The blood in the second EDTA bottle was separated using a swinging bucket centrifuge, the plasma was divided into aliquots and stored at $-20^{\circ} \mathrm{C}$ for analysis of xanthine oxidase activity according to manufacturer's instruction, the remaining three milliliters of blood was put in a lithium heparin bottle and the plasma derived also separated using a swinging bucket centrifuge was used for creatinine assay.

Complete blood count (CBC) was performed for the study population using SYSMEX analyzer (XS 1000i model). Reticulocyte count was determined manually by microscopic examination of new methylene blue stained freshly prepared smears by two clinical laboratory professionals. Peripheral blood film review was also carried out manually by microscopic examination of May Grunwald Giemsa stained smears to determine the number of irreversible sickle cells and nucleated red blood cells.

Plasma xanthine oxidase activity was carried out by using Human Xanthine Oxidase activity Enzyme Linked Immunosorbent Assay kit (produced by Sunlong in China).

\subsection{Statistical Analysis}

Data were analyzed using SPSS version 20.0 (Statistical Package for Social Sciences, Inc., Chicago, Ill). The descriptive data were presented as means \pm standard deviation except otherwise stated. Frequencies were presented in tables. One-way ANOVA (Analysis of Variance) was used to compare means of the independent variables. Significant results were subjected to post-hoc analyses for pair wise comparisons. Spearman analysis was performed for correlation of the biochemical parameters and xanthine oxidase activity with severity of bone pain crisis and steady 
state groups. Results were considered statistically significant if $\mathrm{p}<0.05$.

\section{Results}

\subsection{Clinical Characteristics of Study Participants with Sickle Cell Anaemia}

The mean age of participant in steady state group and BPC group were 30 years and 27 years respectively while the male to female ratio in steady state group and BPC group were 8:7 and 7:8 respectively. The clinical characteristics of the steady state and bone pain crisis groups showed that the mean age at diagnosis of SCA were 26 and 33 months respectively while the mean duration of last episode crisis prior to this study were 7.6 and 6 months respectively. The mean packed cell volume for BPC and steady state groups were $23.93 \pm 3.61 \%$ and $23.20 \pm 3.61 \%$ respectively. The mean body mass index (BMI) in the steady state and BPC group were $22.1 \mathrm{~kg} / \mathrm{m}^{2}$ and $21.6 \mathrm{~kg} / \mathrm{m}^{2}$ respectively, $(p=0.22)$.

\subsection{Total Summary Pain Score}

Patients' and physicians' perceptions were combined as Total Summary Pain Score (TSPS) to get a more objective pain score. One -third 10 (33\%) each of the BPC group had mild TSPS, moderate TSPS and severe TSPS (figure 1). There were multiple involved bone pain sites per patient at presentation. Bones of the lower limb were most frequently affected (number/percentage of times) followed by upper limb and spine. The lease frequent was the rib pain. The mean number of site with BPC in mild TSPS group, Moderate TSPS group and severe TSPS group were 2.6, 2.3 and 3.1 respectively.

\subsection{Haematological and Biochemical Parameters of Participants with Sickle Cell Anaemia and Haemoglobin a Control}

There was significantly elevated total white blood cells and absolute neutrophil count in the BPC group than the steady state group $\left(12.34 \pm 3.87 \times 10^{3} / \mu \mathrm{L}\right.$ and $7.91 \pm 3.51$ $\mathrm{x} 10^{3} / \mu \mathrm{L}$ vs $10.00 \pm 2.26 \times 10^{3} / \mu \mathrm{L}$ and $5.53 \pm 2.08 \times 10^{3} / \mu \mathrm{L}$ respectively, $p=0.007$ and 0.001 respectively. The number of irreversibly sickle cells was higher in the bone pain crisis group than in the steady state group.

However, the mean reticulocyte counts in participants with $\mathrm{BPC}$ and steady state group $(2.34 \pm 0.56 \%$ and $2.27 \pm 0.73 \%)$ were comparable $p=0.922$ (table 2). None of the participants had nucleated red blood cells on the peripheral blood film. The mean plasma xanthine oxidase activity was significantly higher in the BPC group $(164.66 \pm 46.48 \mathrm{IU} / \mathrm{L})$ than in the steady state group $(95.13 \pm 28.10 \mathrm{IU} / \mathrm{L}) p=0.000$ and controls (72.37 \pm 24.52$) p=0.000$ (table 2). Also the mean plasma xanthine oxidase activity was significantly higher in the steady state group $(95.13 \pm 28.10 \mathrm{IU} / \mathrm{L})$ than in the controls $p=$
0.032. There was no difference in the creatinine concentration of the 3 groups of the participants (table 2).

\subsection{Comparison of Xanthine Oxidase in the Different Bone Pain Crises Severity Groups}

The mean xanthine oxidase activity in severe BPC group $(195.45 \pm 40.32 \mathrm{IU} / \mathrm{L})$ was significantly higher than in mild BPC group $(142.21 \pm 36.42 \mathrm{IU} / \mathrm{L})(p=0.024)$. However, there was no significant difference between the plasma xanthine oxidase in the moderate BPC $(153.27 \pm 48.62 \mathrm{IU} / \mathrm{L})$ and mild BPC $(142.21 \pm 36.42 \mathrm{IU} / \mathrm{L})$. There was also no significant difference between the plasma xanthine oxidase in the severe BPC (195.45 $\pm 40.32 \mathrm{IU} / \mathrm{L})$ and moderate BPC (153.27士 48.62IU/L) (table 3).

Comparison of xanthine oxidase activity showed that the mean xanthine oxidase activity in severe BPC group $(195.45 \pm 40.32 \mathrm{IU} / \mathrm{L})$ was significantly higher than in steady state group $(95.13 \pm 28.10 \mathrm{IU} / \mathrm{L})(p=0.000) \quad$ (table 4). The xanthine oxidase activity in the mild bone pain crisis $(142.21 \pm 36.42 \mathrm{IU} / \mathrm{L})$ and moderate bone pain crisis $(153.27 \pm$ 48.62IU/L) were also significantly higher than xanthine oxidase activity in the steady group $(p=0.013$ and 0.028 respectively) (table 4).

\subsection{Correlation Analysis of Xanthine Oxidase with Severity of Bone Pain Crisis}

There is significantly low positive correlation between the mean plasma xanthine oxidase and severity of bone pain crisis $(\mathrm{r}=0.396, \mathrm{p}$-value $=0.030)$ (figure 2 ).

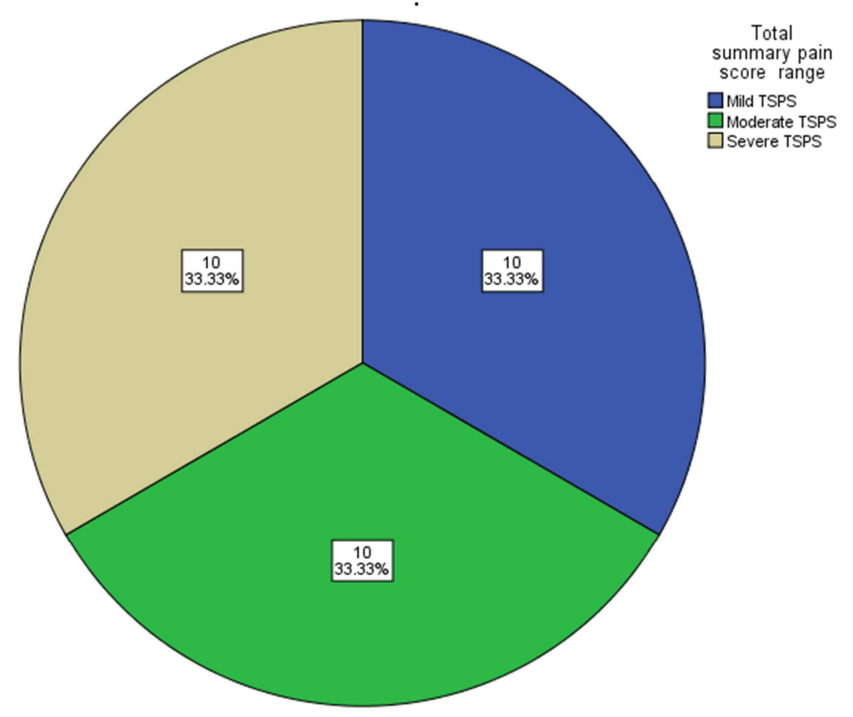

Figure 1. Total summary pain score of sickle cell anaemia patients with bone pain crisis.

TSPS, total summary pain score; PS, Pain score based on patient's verbal numerical score 0-10; DP, Duration of Pain before presentation; PB, Patient's Behavior during examination at presentation; AA, Analgesic administered to relief pain; SCA, sickle cell anaemia; N, Number of participants. 
Table 2. Haematological and Biochemical Parameters of Haemoglobin A Controls (HbA) and Sickle Cell Anaemia Patients in Bone Pain Crisis (BPC) and during Steady State (STEADY).

\begin{tabular}{|c|c|c|c|c|c|c|}
\hline \multirow{3}{*}{ Parameter } & \multirow{3}{*}{$\begin{array}{l}\text { HbA } \\
A \\
X \pm \text { SD } \\
\end{array}$} & \multirow{3}{*}{$\begin{array}{l}\text { BPC } \\
\text { B } \\
X \pm \text { SD }\end{array}$} & \multirow{3}{*}{$\begin{array}{l}\text { STEADY } \\
\mathrm{C} \\
\mathrm{X} \pm \text { SD } \\
\end{array}$} & \multicolumn{3}{|l|}{ P value } \\
\hline & & & & \multirow{2}{*}{ A vs B } & \multirow{2}{*}{ A vs $\mathrm{C}$} & \multirow{2}{*}{ B vs C } \\
\hline & & & & & & \\
\hline Haematocrit (\%) & $43.11 \pm 3.59 \%$ & $23.93 \pm 3.61 \%$ & $23.20 \pm 3.29 \%$ & $0.000^{*}$ & $0.000 *$ & 0.727 \\
\hline $\mathrm{WBC}\left(\mathrm{x} 10^{3} / \mu \mathrm{L}\right)$ & $5.91 \pm 2.25$ & $12.34 \pm 3.87$ & $10.00 \pm 2.26$ & $0.000 *$ & $0.000^{*}$ & $0.007 *$ \\
\hline Neutrophils $\left(\times 10^{3} / \mathrm{L}\right)$ & $2.94 \pm 1.60$ & $7.91 \pm 3.51$ & $5.53 \pm 2.08$ & $0.000^{*}$ & $0.000^{*}$ & $0.001 *$ \\
\hline Lymphocytes $\left(\times 10^{3} / \mathrm{L}\right)$ & $2.28 \pm 0.86$ & $3.18 \pm 1.20$ & $3.16 \pm 0.90$ & $0.002 *$ & $0.003^{*}$ & 0.996 \\
\hline Monocytes $\left(\times 10^{3} / \mu \mathrm{L}\right)$ & $0.46 \pm 0.20$ & $0.97 \pm 0.68$ & $0.89 \pm 0.49$ & $0.001 *$ & $0.004 *$ & 0.856 \\
\hline Eosinophils $\left(\times 10^{3} / \mu \mathrm{L}\right)$ & $0.18 \pm 0.14$ & $0.17 \pm 0.07$ & $0.23 \pm 0.14$ & 0.967 & 0.233 & 0.147 \\
\hline Basophils $\left(\times 10^{3} / \mu \mathrm{L}\right)$ & $0.05 \pm 0.03$ & $0.07 \pm 0.03$ & $0.08 \pm 0.04$ & 0.131 & 0.046 & 0.887 \\
\hline Platelets $\left(\times 10^{3} / \mu \mathrm{L}\right)$ & $269.59 \pm 66.91$ & $379.85 \pm 124.71$ & $329.08 \pm 123.96$ & $0.000^{*}$ & 0.091 & 0.172 \\
\hline \multicolumn{7}{|l|}{$\mathrm{RBC}$ indices } \\
\hline MCV (fL) & $84.13 \pm 7.30$ & $81.32 \pm 9.56$ & $83.23 \pm 5.82$ & 0.374 & 0.904 & 0.632 \\
\hline $\mathrm{MCH}(\mathrm{pg})$ & $27.83 \pm 2.89$ & $27.65 \pm 3.78$ & $29.89 \pm 2.83$ & 0.977 & $0.049 *$ & $0.029 *$ \\
\hline $\mathrm{MCHC}(\mathrm{g} / \mathrm{dL})$ & $32.53 \pm 1.78$ & $33.36 \pm 1.41$ & $32.95 \pm 1.46$ & 0.072 & 0.580 & 0.585 \\
\hline ISC (per HPF) & & $8.97 \pm 5.31$ & $3.23 \pm 1.59$ & & & $0.000^{*}$ \\
\hline Retic count $(\%)$ & $1.50 \pm 0.61$ & $2.27 \pm 0.73$ & $2.34 \pm 0.74$ & $0.000^{*}$ & $0.000 *$ & 0.922 \\
\hline NRBC (Cells/100WBC) & 0.00 & 0.00 & 0.00 & & & \\
\hline Xanthine oxidase activity (IU/L) & $72.37 \pm 24.52$ & $164.66 \pm 46.48$ & $95.13 \pm 28.10$ & $0.000^{*}$ & $0.032 *$ & $0.000^{*}$ \\
\hline Creatinine (mg/dL) & $0.92 \pm 0.39$ & $0.97 \pm 0.37$ & $0.98 \pm 0.47$ & 0.887 & 0.882 & 0.613 \\
\hline
\end{tabular}

*statistically significant; NLR, Neurtophil-lymphocyte ratio: absolute neutrophil count divided by absolute lymphocyte count; MCV, mean cell volume; MCH, mean cell haemoglobin; MCHC mean cell haemoglobin concentration. ISC, irreversible sickle cell index; Retic count, Reticulocyte count; RBC indices, Red blood cell indices; NRBC, Nucleated red blood cells; X, mean; SD, standard deviation; HPF, High power field.

Table 3. Haematological and Biochemical Parameters of Different Bone Pain Crisis (BPC) severity groups in the SCA patients.

\begin{tabular}{|c|c|c|c|c|c|c|}
\hline \multirow{3}{*}{ PARAMETERS } & \multirow{3}{*}{$\begin{array}{l}\text { Mild BPC } \\
\mathbf{A} \\
X \pm S\end{array}$} & \multirow{3}{*}{$\begin{array}{l}\text { Moderate BPC } \\
\text { B } \\
X \pm S D\end{array}$} & \multirow{3}{*}{$\begin{array}{l}\text { Severe BPC } \\
\mathbf{C} \\
\mathbf{X} \pm \text { SD }\end{array}$} & \multicolumn{3}{|l|}{ P Value } \\
\hline & & & & \multirow{2}{*}{ A vs B } & \multirow{2}{*}{ A vs $C$} & \multirow{2}{*}{ B vs $\mathrm{C}$} \\
\hline & & & & & & \\
\hline Haematocrit (\%) & $24.90 \pm 2.33$ & $22.5 \pm 2.93$ & $24.08 \pm 4.70$ & 0.719 & 0.998 & 0.911 \\
\hline $\mathrm{WBC}\left(\mathrm{x} 10^{3} / \mu \mathrm{L}\right)$ & $11.08 \pm 2.12$ & $15.47 \pm 4.70$ & $11.31 \pm 3.46$ & $0.026^{*}$ & 1.000 & $0.029 *$ \\
\hline Neutrophils $\left(\times 10^{3} / \mu \mathrm{L}\right)$ & $6.67 \pm 1.16$ & $10.70 \pm 3.56$ & $7.08 \pm 3.95$ & $0.016^{*}$ & 0.997 & $0.030 *$ \\
\hline Lymphocytes $\left(\times 10^{3} / \mu \mathrm{L}\right)$ & $3.16 \pm 1.27$ & $3.45 \pm 1.23$ & $2.94 \pm 0.69$ & 1.000 & 0.697 & 0.715 \\
\hline Monocytes $\left(\times 10^{3} / \mu \mathrm{L}\right)$ & $0.75 \pm 0.41$ & $1.07 \pm 0.83$ & $0.93 \pm 0.38$ & 0.771 & 0.642 & 1.000 \\
\hline Eosinophils $\left(\mathrm{x} 10^{3} / \mu \mathrm{L}\right)$ & $0.14 \pm 0.06$ & $0.16 \pm 0.07$ & $0.19 \pm 0.09$ & 1.000 & 0.920 & 0.993 \\
\hline Basophils $\left(\times 10^{3} / \mu \mathrm{L}\right)$ & $0.07 \pm 0.04$ & $0.07 \pm 0.04$ & $0.08 \pm 0.03$ & 1.000 & 0.701 & 1.000 \\
\hline NLR & $2.30 \pm 0.26$ & $3.45 \pm 1.65$ & $2.31 \pm 1.75$ & 0.293 & 0.939 & 0.693 \\
\hline Platelets $\left(\times 10^{3} / \mu \mathrm{L}\right)$ & $345.48 \pm 145.44$ & $453.61 \pm 152.81$ & $359.33 \pm 57.85$ & 0.342 & 0.701 & 0.446 \\
\hline RBC indices MCV (fL) & $80.04 \pm 11.76$ & $85.03 \pm 10.77$ & $79.83 \pm 6.38$ & 0.76 & 1.000 & 0.715 \\
\hline $\mathrm{MCH}(\mathrm{pg})$ & $26.54 \pm 3.67$ & $28.96 \pm 4.56$ & $28.45 \pm 3.31$ & 0.633 & 0.948 & 0.944 \\
\hline $\mathrm{MCHC}(\mathrm{g} / \mathrm{dL})$ & $33.58 \pm 1.45$ & $32.64 \pm 1.75$ & $33.67 \pm 1.01$ & 0.807 & 1.000 & 0.715 \\
\hline Xanthine oxidase activity (IU/L) & $142.21 \pm 36.42$ & $153.27 \pm 48.62$ & $195.45 \pm 40.32$ & 0.993 & $0.024 *$ & 0.259 \\
\hline Creatinine $(\mathrm{mg} / \mathrm{dL})$ & $0.85 \pm 0.38$ & $1.00 \pm 0.43$ & $1.06 \pm 0.29$ & 0.892 & 0.789 & 0.998 \\
\hline
\end{tabular}

*statistically significant at $\mathrm{p}<0.05$; NLR, Neurtophil-lymphocyte ratio = absolute neutrophil count divided by absolute lymphocyte count; MCV, mean cell volume; $\mathrm{MCH}$, mean cell haemoglobin; $\mathrm{MCHC}$ mean cell haemoglobin concentration; X, mean; SD, standard deviation.

Table 4. Plasma Xanthine oxidase level of Different Bone Pain Crisis (BPC) severity groups and steady state in the SCA patients.

\begin{tabular}{|c|c|c|c|}
\hline \multirow{3}{*}{ Severity of BPC XO } & \multicolumn{2}{|l|}{ Steady state XO } & \multirow{3}{*}{$\frac{\text { P-value }}{\text { A vs B }}$} \\
\hline & $\mathbf{A}$ & B & \\
\hline & $\mathbf{X} \pm \mathbf{S}$ & $\mathbf{X} \pm \mathbf{S}$ & \\
\hline mild BPC (IU/L) & $142.21 \pm 36.42$ & $95.13 \pm 28.10$ & $0.013 *$ \\
\hline moderate BPC (IU/L) & $153.27 \pm 48.62$ & $95.13 \pm 28.10$ & $0.028^{*}$ \\
\hline severe BPC (IU/L) & $195.45 \pm 40.32$ & $95.13 \pm 28.10$ & $0.000^{*}$ \\
\hline
\end{tabular}

*statistically significant at $\mathrm{p}<0.05 ; \mathrm{X}$, mean; $\mathrm{SD}$, standard deviation; A, xanthine oxidase concentration in different bone pain crises severity group; B, xanthine oxidase concentration in steady state. 


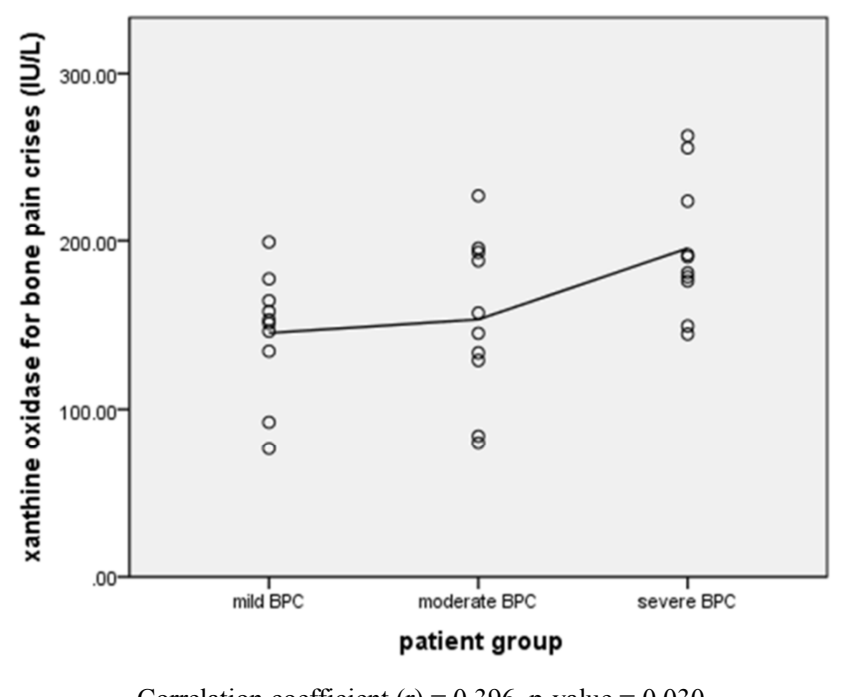

Correlation coefficient $(\mathrm{r})=0.396, \mathrm{p}$-value $=0.030$.

Figure 2. Correlation of xanthine oxidase activity with total summary pain score in sickle cell patients with bone pain crisis: $n=30$.

\section{Discussion}

This study showed a significantly higher plasma xanthine oxidase activity in patients with sickle cell anaemia in bone pain than patients with sickle cell anaemia in steady state and $\mathrm{HbA}$ controls. There is an attempt in this study to link the animal experimental work carried out by many researches to clinical scenario in SCA patients. Elevated xanthine oxidase activity has been associated with hypoxia-induced vasoocclusive crisis in SCD mice and humans $[4,18]$.

The significantly high mean plasma xanthine oxidase activity in patients with sickle cell anaemia in BPC compared to the activity in $\mathrm{HbA}$ control group support the study done by Hassoun which showed increased mRNA expression of $\mathrm{XD} / \mathrm{XO}$ in cultured endothelial cells obtained from pulmonary arteries of calves and pigs placed in hypoxic conditions [24]. The pro-inflammatory action of ROS derived from $\mathrm{XO}$ activity is intricately linked to the pathophysiology of VOC [25]. The relationship of vaso-occlusion responsible for bone pain crisis and hypoxia is evident by irreversible sickle cell index that was significantly higher in patients with SCA presenting BPC that in steady state in this study. The transcriptional and post-translational up-regulation of $\mathrm{XD} / \mathrm{XO}$ is induced by severe hypoxia [26, 27]. A study has shown that modest hypoxia as occur in heart failure could induce significant elevation of xanthine oxidase dependent ROS expression, activity, export from endothelial cells, and XO-dependent ROS production [28]. XD/XO has been indicated as the major cause of oxidative stress after hypoxia/reoxygenation and ischaemia/reperfusion and that ROS production by activated neutrophils, as proposed for vascular reperfusion injury, is not required [26]. The absence of blood allows the exclusion of neutrophil components from the generation of ROS. XO has the ability to stick to vascular cells because it binds to sulphated glycosaminoglycans on the endothelial cell surface which is heparin reversible in studies with cultured endothelial cells [26]. This may be part of the pathway heparin works in VOC crisis and make it an important therapy in VOC.

The significant difference in the mean $\mathrm{XO}$ activity between the sickle cell anaemic patients in steady state and $\mathrm{HbA}$ control group observed in this study is in agreement with the findings by Aslan et al. who demonstrated significant difference in the mean plasma $\mathrm{XO}$ in sickle mice and $\mathrm{HbA}$ control human. Though, Aslan used HPLC method to assay for plasma $\mathrm{XO}$ estimation which is a less specific method of assessment of plasma XO. The HPLC measures both plasma xanthine oxidase and xanthine dehydrogenase with the use of amount of uric acid generated to indirectly measure XO activity. Also unlike this study, the participants with sickle cell anaemia studied by Aslan et al were not categorized into steady state and bone pain crisis [4]. However, this was not in support of Osarogiagbon et al. who demonstrated insignificant difference in the mean XO activity between the sickle cell anaemic patients in steady state and $\mathrm{HbA}$ control transgenic mice. Meanwhile, Osarogiagbon et al study showed increased conversion of XD to $\mathrm{XO}$ and significant increase in the mean $\mathrm{XO}$ in the sickle mice when attempt was made to mimic vaso-occlusive crisis state in patients with sickle cell anaemia by exposure of the mice to 2 hours of hypoxia [18]. The xanthine oxidase activity in the SCA patients in bone pain crisis significantly correlate with the severity of the bone pain increases. There is also evidence of significantly increased xanthine oxidase activity in patients with severe BPC when compared with SCA patients with mild BPC. Although extensive internet search does not show any study that directly correlate xanthine oxidase activity with severity of bone pain crisis in patients with sickle cell anaemia in bone pain crisis. However, this finding was in support of the study by Hughes et al. and chang-il et al. which showed a positive and negative correlation of endothelin-1 and nitric oxide respectively with xanthine oxidase [29, 30]. Endothelin-1 is a vaso-constrictor which is implicated in the pathogenesis of vaso-occlusive crisis in sickle cell disease, a study showed a positive correlation between Endothelin-1 and severity of bone pain crisis in patient with bone pain crisis. This indirectly implies that there is positive correlation between plasma xanthine oxidase activities with severity of bone pain crisis in patients with sickle cell anaemia in bone pain crisis [23].

Nitric oxide is a potent vasodilator, scavenging of this by xanthine oxidase is implicated in the pathogenesis of vasoocclusive crisis in sickle cell disease [30]. A dose dependent inverse relationship was noticed between nitric oxide concentration and xanthine oxidase activity was observed in a study [30]. This indirectly agrees with the finding of positive correlation between plasma xanthine oxidase activities with severity of bone pain crisis in patients with sickle cell anaemia in bone pain crisis in this study. However, it disagrees with the negative correlation between nitric oxide concentration and xanthine oxidase activity was found in another [31]. 


\section{Conclusion and Recommendations}

\subsection{Conclusion}

This study has established that xanthine oxidase activity was high in all bone pain crisis group in patients with SCA presenting in bone pains crisis than steady state and $\mathrm{HbA}$ individual. It also establishes positive correlation between xanthine oxidase activities and severity of bone pain crisis in these patients In view of the aforementioned, targeting xanthine oxidase enzyme with Allopurinol (xanthine oxidase inhibitor) could serve as therapeutic intervention in preventing reperfusion injury and its complications in patients with sickle cell anaemia.

\subsection{Recommendations}

A longitudinal study on the $\mathrm{HbS}$ participants in bone pain crisis and after resolution of bone pain crisis (preferably in the steady state) will be more effective study and will give a better and more reliable result to draw our inference from as this will exclude a lot of confounding factors that might not have been noticed in longitudinal studies. This observational cross-sectional study may not provide adequate definite information about cause-and-effect relationships of xanthine oxidase activity with severity of bone pain crisis as it offers only a snapshot of a single moment in time; they do not consider what happens before or after the snapshot is taken.

Objective exclusion of some of the things in the exclusion criteria such as objective measurement of electrolyte, urea, creatine, bilirubin, liver enzymes, albumin and plasma proteins will have been more appropriate than asking or carrying out physical examinination for co-exis ting sickle cell nephropathy or liver disease. This is because some of them might have sickle cell nephropathy or liver disease without their knowledge or clinical evidence.

A large population study will more appropriately represent the study population as there are different types of sickle cell disease severity. The sample size of this study may not adequately represent the sample population as the $\mathrm{HbS}$ participant studied might not capture all the $\mathrm{HbS}$ disease severity which might affect some of the parameters measured.

Xanthine oxidase could be investigated further as possible targets of therapeutic intervention in patients with severe bone pain crisis.

The effect of hydroxyurea on xanthine oxidase activity in patients with sickle cell anaemia should be studied.

The relationship between xanthine oxidase, sickle cell anaemia and their haplotypes should also be studied.

\section{Limitations of the Study}

The study is a descriptive cross-sectional.

The phenotypic variation in the participants with sickle cell anaemia as a result of genetic modifiers mainly from the haplotypes and co-inheritance with thalassaemias was not investigated.

\section{Conflict of Interest}

All the authors do not have any possible conflicts of interest.

\section{References}

[1] Adekile A. What's new in the pathophysiology of sickle cell disease? Med Princ Pr. 2013; 22 (4): 311-2.

[2] Darbari DS, Wang Z, Kwak M, Hildesheim M, Nichols J, Allen D, et al. Severe painful vaso-occlusive crises and mortality in a contemporary adult sickle cell anemia cohort study. PLoS One [Internet]. 2013 Nov 5; 8 (11): e79923e79923. Available from: https://pubmed.ncbi.nlm.nih.gov/24224021.

[3] Adekunle EA, Olaniyi JA OW. Adult Sickle Cell Anaemia Patients in Bone Pain Crisis have elevated Pro-Inflammatory Cytokines. Mediterr J Hematol Infect Dis. 2018; 10 (1): 1-9.

[4] Aslan M, Ryan T, Adler B, Townes T, Parks D, Thompson J, et al. Oxygen radical inhibition of nitric oxide-dependent vascular function in sickle cell disease. Proc Natl Acad Sci U S A. 2001; 98 (26): 15215-20.

[5] Stark K, Seubert P, Lynch G, Baudry M. Proteolytic conversion of xanthine dehydrogenase to xanthine oxidase: evidence against a role for calcium-activated protease (calpain). Biochem Biophys Res Commun [Internet]. 1989 Dec 15; 165 (2): 858-64. Available from: https://pubmed.ncbi.nlm.nih.gov/2557023.

[6] Pal P, Alex N, Csaba S. Therapeutic Effect of Xanthine Oxidase Inhibitors: Renaissance Half a Century after the Discovery of Allopurinol. Pharmacol Rev. 2006; 58 (1): 87 114.

[7] Carcao M, Dawn C, Uptom A, Jeremy F, Nadya C. Acute Painful episodes vaso-occlusive Crisis: Guidelines for management in Children with Sickle cell disease. Clin Pract Guidel. 2016; 5: 1-9.

[8] Ramos C, Pou S, Britigan B, Cohen M, Rosen G. Spin trapping evidence for myeloperoxidase-dependent hydroxyl radical formation by human neutrophils and monocytes. J Biol Chem. 1992; 267: 8307-8312.

[9] Contributors W. Xanthine oxidase [Internet]. Wikipedia, The Free Encyclopedia. 2019 [cited 2020 Feb 8]. p. Xanthine oxidase. Available from: https://en.wikipedia.org/w/index.php?title=Xanthine_oxidase \&oldid $=930242442$.

[10] Nagabudu E, Fabry ME, Nagel RL and RM. heme degradation and oxidative stress in murine model of hemoglobinopathies. Blood cells Mol Dis. 2008; 41: 61-6.

[11] Sheng K, Shariff M, Hebbel RP. Comparative Oxidation of Hemoglobins A and S. Blood [Internet]. 1998; 91 (9): 3467$70 . \quad$ Available from: http://bloodjournal.hematologylibrary.org/content/91/9/3467.a bstract.

[12] Battelli MG, Polito L, Bortolotti M, Bolognesi A. Xanthine Oxidoreductase-Derived Reactive Species: Physiological and Pathological Effects. Reed TT, editor. Oxid Med Cell Longev [Internet]. 2016; 2016: 3527579. Available from: https://doi.org/10.1155/2016/3527579. 
[13] Morris, C, Suh, J, Hagar, W, Larkin S BD. Erythrocyte glutamine depletion, altered redox environment, and pulmonary hypertension in sickle cell disease. Blood. 2008; 111: 402-410.

[14] Perricone AJ, Vander Heide RS. Novel therapeutic strategies for ischemic heart disease. Pharmacol Res [Internet]. 2014; 89 $36-45$. Available

from: http://dx.doi.org/10.1016/j.phrs.2014.08.004.

[15] Aslan M, Thornley-Brown D, Freeman B a. Reactive species in sickle cell disease. Ann N Y Acad Sci. 2000; 899: 375-91.

[16] Chirico EN, Pialoux V, Lyon D, Lyon CB. Critical Review Role of Oxidative Stress in the Pathogenesis of Sickle Cell Disease. 2012; 64 (January): 72-80.

[17] Fasola F, Adedapo K, Anetor J, Kuti M. Total antioxidants status and some hematological values in sickle cell disease patients in steady state. J Natl Med Assoc. 2007; 99 (8): 891-4.

[18] Osarogiagbon U, Choong S. Reperfusion injury Reperfusion injury pathophysiology in sickle transgenic mice. Blood. 2000; 96: $314-20$

[19] Gardner R V. Sickle Cell Disease: Advances in Treatment. Ochsner J [Internet]. 2018; 18 (4): 377-89. Available from: https: //pubmed.ncbi.nlm.nih.gov/30559624.

[20] Torres L CN. Emerging pharmacotherapeutic approaches for the management of sickle cell disease. Expert Opin. Pharmacother. 2018; 20 (2): 173-86.

[21] White C, Darley-Usmar V, Berrington W, McAdams M, Gore $\mathrm{J}$, Thompson $\mathrm{J}$, et al. Circulating plasma xanthine oxidase contributes to vascular dysfunction in hypercholesterolemic rabbits. Proc Natl Acad Sci U S A. 1996; 93 (16): 8745-9.

[22] Platt O. Pain in Sickle Cell disease. N Engl J Med. 1991; 325 (1): Platt, O. S., et al., Pain in Sickle Cell Disease.
[23] Adekunle E, Olaniyi J, Oladapo W. Adult Sickle CellAnaemia Patients in Bone Pain Crisis have elevated Pro-Inflammatory Cytokines. Mediterr J Hematol Infect Dis. 2018; 10 (1): 1-9.

[24] Hassoun F, Shedd J, Zulueta V. Regulation of endothelial cell xanthine dehydrogenase and xanthine oxidase gene expression by oxygen tension. Am J Physiol. 2004; 10: 163-71.

[25] Mittal M, Siddiqui MR, Tran K, Reddy SP, Malik AB. Reactive oxygen species in inflammation and tissue injury. Antioxid Redox Signal [Internet]. 2013/10/22. 2014 Mar 1; 20 (7): 1126-67. Available from: https://pubmed.ncbi.nlm.nih.gov/23991888.

[26] Battelli M. et al. Pathophysiology of circulating xanthine oxidoreductase: New emergingroles for a multi-tasking enzyme /. Biochim Biophys Acta. 2014; 18 (42): 1502-1517.

[27] Linder N, Martelin M, Lapatto R, Raivio K. Posttranslational inactivation of human xanthine oxidoreductase by oxygen under standard cell culture conditions. Am J Physiol Cell Physiol. 2003; 285 (1): 48-55.

[28] Kelley E et al. Moderate hypoxia induces xanthine oxidoreductase activity in arterial endothelial cells. Free Radic Biol Med. 2006; 40 (6): 952-9.

[29] Hughes AK, Stricklett PK, Padilla E, Kohan DE. Effect of reactive oxygen species on endothelin-1 production by human mesangial cells. Kidney Int. 1996 Jan; 49 (1): 181-9.

[30] Lee C Il, Liu X, Zweier JL. Regulation of xanthine oxidase by nitric oxide and peroxynitrite. J Biol Chem. 2000; 275 (13): 9369-76.

[31] Herken H, Gurel A, Selek S, Armutcu F, Ozen ME, Bulut M, et al. Adenosine Deaminase, Nitric Oxide, Superoxide Dismutase, and Xanthine Oxidase in Patients with Major Depression: Impact of Antidepressant Treatment. Arch Med Res. 2007; 38 (2): 247-52. 